\title{
On anisol and its derivatives
}

\section{M.A. Cahours}

To cite this article: M.A. Cahours (1849) On anisol and its derivatives, Philosophical Magazine Series 3, 34:231, 476-478, DOI: 10.1080/14786444908646276

To link to this article: http://dx.doi.org/10.1080/14786444908646276

$$
\text { 册 Published online: } 30 \text { Apr } 2009 .
$$

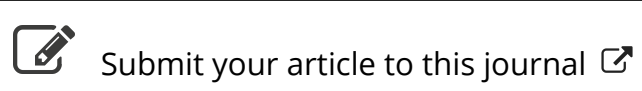

\footnotetext{
Џll Article views: 2
}

Q View related articles $\sqsubset$ 
is added to the sulphate of copper, the same quantity of precipitate is not obtained.

It results from the above-stated experiments, that the quantities of the triple salt vary according to the proportions of water, and whether the sulphate of copper is added to the sulphate of potash, or the reverse; when the proportion of sulphate of potash is increased, a larger quantity of the sulphate of copper is decomposed, but without in any case obtaining bisulphate of potash and the triple salt only.

As the proportions of the triple salt thus formed are variable, it is natural that the solutions which yield it should differ in composition; some are found to contain much of the copper salt, whilst in others the sulphate of potash is in excess.

On subjecting these solutions to careful evaporation, crystals of a double salt, $\ddot{\mathrm{S}} \mathrm{Cu} \ddot{\mathrm{S}} \dot{\mathrm{K}}+6 \mathrm{H}^{2} \mathrm{O}$, are formed, which by two or three successive concentrations separate completely. It is a curious phænomenon to observe such very soluble salts produced so perfect by simple crystallization. The mother-waters eventually resulting from these crystallizations are merely bisulphate of potash.-Ann. de Chim. et de Phys., Mars 1849.

ON OCTOHEDRal AND CUBIC alUM. BY M. J. PERSOz.

It is well known, that when a solution of octohedral alum is saturated with potash, or for a short time put in contact with trissulphate of alumina, it cannot be heated to $140^{\circ} \mathrm{F}$. without hecoming turbid; and there are formed octohedral alum, soluble at all temperatures, and trissulphate of alumina, which is precipitated. When the solution, however, instead of being subjected to so high a temperature, is subjected to evaporation at a gentle heat, cubic alum is obtained, which readily becomes octohedral alum by dissolving it in water slightly acidified with sulphuric acid. It may then be evaporated and redissolved at pleasure without undergoing any alteration. Lastly, if a certain quantity of cubic alum be dissolved in water and boiled, it yields basic sulphate of alumina insoluble in water; and the mother-water and that used in washing, when mixed and evaporated, give only octohedral alum. Hence it is concluded that these two alums are not identical, and that cubic alum contains most alumina.-Ann. de Chim. et de Phys., Mars 1849.

\section{ON ANISOL AND ITS DERIVATIVES. BY M. A. CAHOURS.}

Anisol presenting with respect to toluol (benzoène of $M$. Deville) the same relations of composition that phénol does to benzene, the author resumed the examination of this product, in order to complete his researches respecting the compounds of the anisic series.

It has been shown that anisol treated with fuming nitric acid exchanged 2 or 3 equivalents of hydrogen for 2 or 3 equivalents of hypoazotic vapour. There was therefore wanting in this series of the derivatives of anisol, its first term, that is to say, that which would result from the replacement of 1 equivalent of hydrogen by 
1 equivalent of hypoazotic vapour, and which the author calls in the nomenclature adopted for these compounds mononitric anisol. M. Cahours has succeeded in obtaining it by treating anisol with small portions of fuming nitric acid, taking care to keep the vessel containing the reacting substances extremely cold. Operating with these precautions, a thick liquid of a blackish blue is obtained, which is purified by submitting it, at first, to repeated washings with slightly alkaline water, and afterwards by distilling it, having first digested it over fused chloride of calcium. Thus prepared, mononitric anisol is a liquid of an amber colour and heavier than water. It boils between $503^{\circ}$ and $507^{\circ} \mathrm{F}$., and possesses an aromatic odour. Solution of potash, even when heated, does not alter it. Concentrated sulphuric acid dissolves it when gently heated, and water added to the solution separates the product from the liquor unaltered. Treated with an alcoholic solution of hydrosulphate of ammonia, it is readily acted upon; sulphur is deposited, and the alcohol holds in solution a new organic base, which differs from toluidine only in containing two molecules of oxygen.

Mononitric anisol submitted to analysis yielded nearly-

$$
\begin{aligned}
& 14 \text { eqs. Carbon . . . . . . } 8484 \\
& 7 \text {... Hydrogen. . . . . } 7 \text { 7 } 4.57 \\
& \text { l ... Nitrogen ...... } 14 \quad 9 \cdot 14 \\
& 6 \text {... Oxygen. . . . . . } \frac{48}{153} \quad 31 \cdot 39
\end{aligned}
$$

The substance thus formed differs from anisol by the substitution of one equivalent of hypoazotic acid for one equivalent of hydrogen, which justifies the name of mononitric anisol bestowed upon it.

The analysis of the new base, formed by the action of mononitric anisol and hydrosulphate of ammonia, leads to the formula $\mathrm{C}^{14} \mathrm{H}^{9} \mathrm{NO}^{2}$; it forms a crystalline salt with hydrochloric acid. As mononitric anisol is prepared with difficulty, $M$. Cahours has obtained only a small quantity of it, and he proposes to call it anisidine.

Benzene and binitric cumene being easily acted upon by hydrosulphate of ammonia, and transformed into nitric alkaloids, binitric anisol was submitted to the same reagent. By treating an alcoholic solution of binitric anisol with hydrosulphate of ammonia, an abundant deposit of sulphur is obtained, whilst the alcohol retains in solution a substance which perfectly saturates acids, and forms with them crystallizable acids [salts ?].

The new base thus formed crystallizes in long needles of a reddish brown colour, possessing much lustre; it is insoluble in water, but dissolves readily in boiling alcohol, the greater portion separating on cooling. This alkaloid yields well-formed crystalline salts with sulphuric, nitric and hydrochloric acids; some of them are perfectly colourless when pure.

The analysis of this substance indicated its composition to be-

$$
\begin{aligned}
& 14 \text { eqs. of Carbon ...... } 84 \quad 50.00 \\
& 8 \quad \ldots \text { Hydrogen .... } 88 \text { 8 } 4 \cdot 76 \\
& 2 \quad \ldots \quad \text { Nitrogen...... } 28 \quad 16.67 \\
& 6 \quad \ldots \quad \text { Oxygen ...... } 48 \\
& \overline{168} \overline{100 \cdot 00}
\end{aligned}
$$

It will be observed that this substance differs from the preceding 
only in one equivalent of hydrogen being replaced by one equiva. lent of hypoazotic vapour ; for this reason the author gives it the name of anisidine nitree. This base forms with hydrochloric acid, a colourless salt crystallized in long needles, represented by the formula $\mathrm{CIH}, \mathrm{C}^{14} \mathrm{H}^{8} \mathrm{~N}^{2} \mathrm{O}^{6}$.

The chloroplatinate crystallizes in needles of a golden yellow colour ; its formula is $\mathrm{ClH}, \mathrm{PtCl}^{2}, \mathrm{C}^{14} \mathrm{H}^{8} \mathrm{~N}^{2} \mathrm{O}^{6}$; the nitrate has the form of prisms of considerable size, which are slightly soluble in water; the formula is $\mathrm{NO}^{5}, \mathrm{HO}, \mathrm{C}^{14} \mathrm{H}^{3} \mathrm{~N}^{2} \mathrm{O}^{6}$; the sulphate is very soluble in water, it crystallizes in very fine needles, grouped around a common centre; its formula is $\mathrm{SO}^{9}, \mathrm{C}^{14} \mathrm{H}^{3} \mathrm{~N}^{2} \mathrm{O}^{6}$.

When toluol is treated with fuming nitric acid, it forms two compounds, one of which is liquid, and is the mononitric toluol; the other is crystallized, and is the binitric toluol; when the latter was treated with an alcoholic solution of hydrosulphate of ammonia, it yielded a very fine alkaloid corresponding to anisidine nitrée, differing from it only by two equivalents of oxygen. This new alkali the author calls toluidine nitrée; its formula is $\mathrm{C}^{14} \mathrm{H}^{3} \mathrm{~N}^{2} \mathrm{O}^{4}$.

The number of alkaloids increases daily; their study affords results of great interest, and the hope may be entertained that those presented by nature may eventually be formed by art. M. Würtz has described two very remarkable alkalies obtained by the action of potash on cyanic ather, alcohol, and pyroxylic spirit; petinine, recently discovered by $M$. Anderson in the products of the distillation of animal matters, is to be added to the group. The strong ammoniacal odour, the manifest analogy of the properties of its salts, with those of the salts formed by the alkalies of M. Würtz, induced M. Cahours to suppose that petinine belongs to this series. Adopting the formula $\mathrm{C}^{8} \mathrm{H}^{15} \mathrm{~N}$, proposed by $M$. Gerhardt, from the analysis of the chloroplatinate, it will be seen that petinine is merely butyrammonia $\mathrm{C}^{8} \mathrm{H}^{2}, \mathrm{NH}^{2}$. M. Anderson has also noticed, in the oil derived from the distillation of animal substances, some very volatile alkaline products, among which will probably be found the curious alkalies of M. Würtz.

When fuming nitric acid is made to react upon anisic acid, or nitranisic acid, binitric or trinitric anisol is formed, according to the proportion of the matters reacting and the duration of the reaction; besides these two substances, there is formed, and often in great abundance, an acid which crystallizes from an alcoholic solution as it cools, in the form of rhomboidal plates of a magnificent golden yellow colour; this acid, which M. Cahours calls chrysanisic acid, has a very remarkable composition : it is isomeric with trinitric anisol; consequently it is an homologue of picric acid (phénol trinitrée).

This acid submitted to analysis gave-

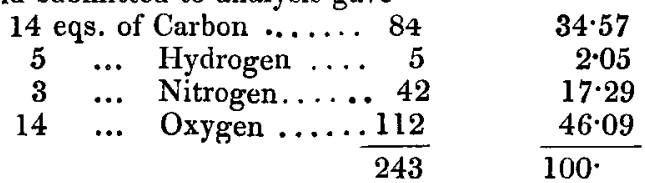

This acid, differently from all others of the same kind, forms a very soluble salt with potash.-Comptes Rendus, March 19, 1849. 